\title{
Microorganisms in the Clouds of Venus
}

\author{
Fred Hoyle ${ }^{1}$ and Chandra Wickramasinghe ${ }^{2,3,4}$ \\ ${ }^{1}$ Deceased, 2001 \\ ${ }^{2}$ University of Buckingham, Buckingham, UK \\ ${ }^{3}$ Centre for Astrobiology, University of Ruhuna, Sri Lanka \\ ${ }^{4}$ National Institute of Fundamental Studies, Kandy, Sri Lanka \\ Email: ncwick@gmail.com
}

\begin{abstract}
The beginnings of a theory of Venusian aerobiology were developed by us as early as 1982 and published in a monograph from which an extract is reproduced here. The reprinted form of this material with new annotations would be of use to modern investigators who are revisiting these ideas.
\end{abstract}

Keywords: Venus, Venusian clouds, bacterial cycle

\section{Clouds of Venus as Microbial Habitats}

Figure 1 shows the temperature profile in the clouds of Venus.
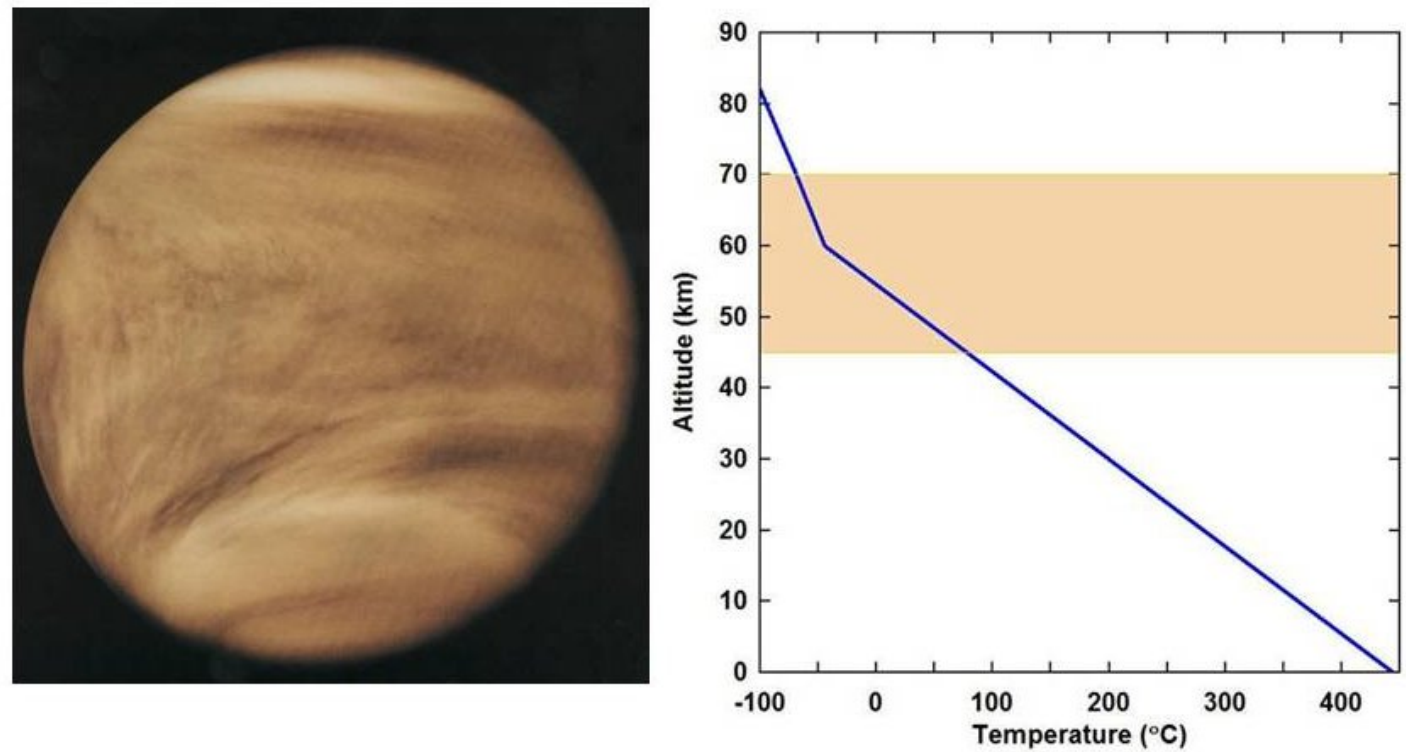

Figure 1. The clouds of Venus: height-temperature profile.

The upper clouds of Venus produce a rainbow, indicating the cloud particles are spherical and that they have sizes in the region of $1 \mu \mathrm{m}$ (Coffeen and Hansen, 1974). The distribution of particle sizes actually measured in the upper clouds by Pioneer Venus is shown in Fig. 2 (Knollenberg and Hunten,

Reprinted from Space Travellers, The Bringers of Life (Chapter 12) by Fred Hoyle and Chandra Wickramasinghe (Univ. Coll. Cardiff Press, 1982, copyright reverted to authors). The original chapter was reformatted by Chandra Wickramasinghe. No references to more recent work is included in the text to preserve the historical record as of 1982. 
1970). Although a considerable amount of further argument is needed before one can be satisfied about details, the correspondence of the observed particle sizes to those of bacteria is striking.

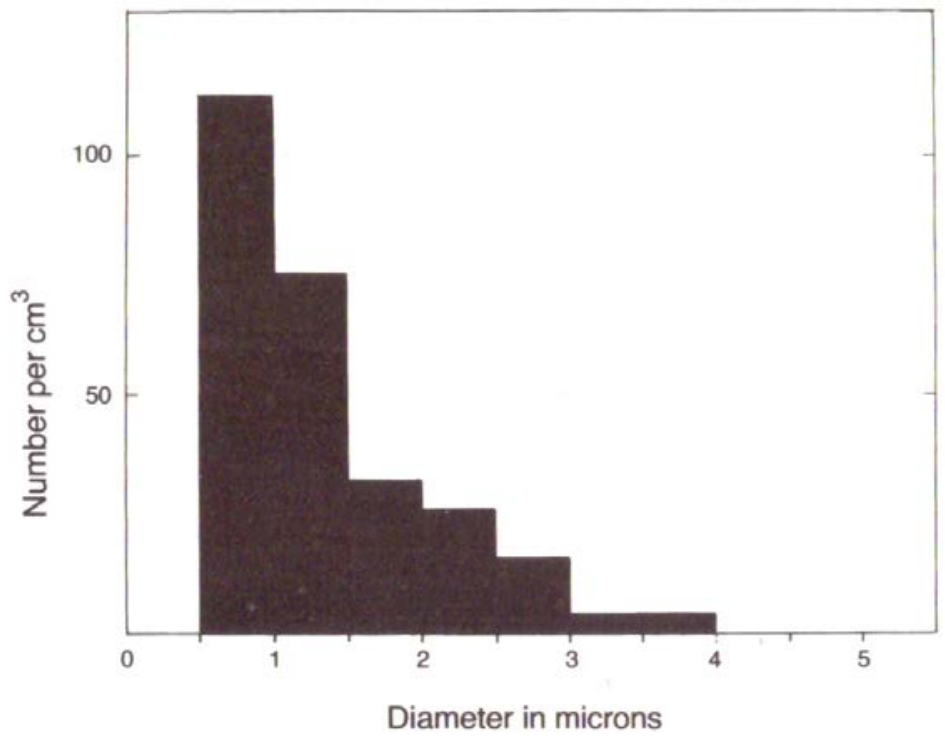

Figure 2. Distribution of particle sizes in the upper clouds of Venus (55-65km) measured by Pioneer Venus Orbiter (1978).

There are two ways in which bacteria can be spherical in shape, one through forming spores and the other through restriction to the class of micrococci. Of these, spores appear the more likely possibility, for the reason that the clouds of Venus are in convective motion, extending from the upper level at an altitude of $65-70 \mathrm{~km}$ down to an altitude of $45 \mathrm{~km}$ (Fig.1). The temperature at $45 \mathrm{~km}$ is about $75^{\circ} \mathrm{C}$ and at the top is about $-25^{\circ} \mathrm{C}$. While survival over this range is easily possible for bacteria, the repeated variations of temperature caused by a circulating cloud system would be better resisted by bacteria capable of forming spores which are still hardier than the bacteria giving rise to them. Thus, bacteria could be rod-shaped in the lower warmer regions, but giving place to spherical spores in the cold upper regions of the clouds. In this way there is no requirement for the bacteria to be exclusively micrococci.

\section{Properties of Bacteria in Clouds}

It is well known that a quantity called the refractive index of a particle is relevant to its light scattering properties (Wickramasinghe, 1973). The refractive index of water is about 1.33 and that of biological material about 1.5. Bacterial spores contain about $25 \%$ water by weight, which causes them to behave like a uniform particle with refractive index 1.44, which is exactly what is shown by observations on the degree of polarization of the upper clouds of Venus (Figure 1).

The refractive index of sulphuric acid is 1.48, and sulphuric acid droplets with $25 \%$ water would behave like uniform particles with refractive index 1.44. But this explanation of the upper clouds of Venus fails on a number of important points. There is no reason for such droplets to have sizes of 0.6$1.2 \mu \mathrm{m}$ (Fig.2). Sulphuric acid droplets could, and very likely would, have a much broader size distribution than that shown in Fig.2. The $25 \%$ water concentration is an arbitrary choice, whereas for bacterial spores there is no choice, about $25 \%$ is what the water must be. The chemical sampler carried by Pioneer Venus (1987) measured vapour pressures of oxygen and sulphur dioxide in the cloud regions that were thousands of times lower than one can easily have in the laboratory, and yet, even at the much higher laboratory concentrations, oxygen and sulphur dioxide do not go easily to sulphur trioxide, and thence by the addition of water to sulphuric acid. Commercial sulphuric acid is produced in two ways, the old way by a complex of reactions involving nitric acid, and the modern way by catalytic processes involving either platinum metal or vanadium oxide. Inorganic catalysts like platinum tend to 
become 'poisoned' under natural conditions, however - they take part in other reactions which change them.

The highly effective catalysts in nature are bacteria, which not only maintain themselves (which is all that inorganic catalysts can do) but actually increase in number through the chemical reactions they promote. Hence to produce some sulphuric acid, which is apparently required to explain certain details of the infrared radiation emitted by the clouds of Venus, it is to bacteria that we should look. Sulphur bacteria are yellow in colour, and it is to their presence (among other non-yellow bacteria) that we attribute the pale-yellow colour of the light reflected by Venus. Sulphuric acid is colourless, on the other hand, and droplets of it would not produce any such colouring.

\section{Cycles of Bacterial Replication}

Water is not a particularly abundant constituent of the atmosphere of Venus. The second atmospheric sample taken by Pioneer Venus at an altitude of about $46 \mathrm{~km}$ near the base of the lower clouds gave about $0.5 \%$ water. With this concentration, and choosing $-10^{\circ} \mathrm{C}$ as the lowest temperature at which the bacteria replicate, the relative humidity can be calculated to be about $85 \%$, which is adequate for bacteria with an appreciable internal content of dissolved salts. It is important here that the problem of maintaining liquid water inside a bacterium is not simply evaporation from a free water surface but of evaporation from the outer surface of the bacterial membrane, which is markedly water-attractive. At $85 \%$ relative humidity only a quite small extra bit of holding power against evaporation of water molecules is sufficient to stop a bacterium from drying out in the schematic manner shown in Fig.3.

However, under exceedingly dry conditions, near zero percent humidity, bacteria must largely dry out. As bacteria circulated through the middle and lower cloud regions of Venus, they would be subject to relative humidity values that ranged from near zero in the hotter, lower regions to about $85 \%$ in the cooler, upper regions. This would provide a natural water pump with alternating phases of filling with water and of subsequent evaporation, and with each water-filling episode giving a fresh supply of nutrients to the interior of the cell.

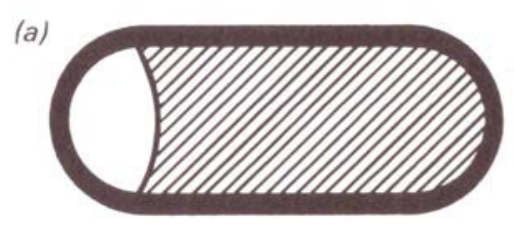

(b)
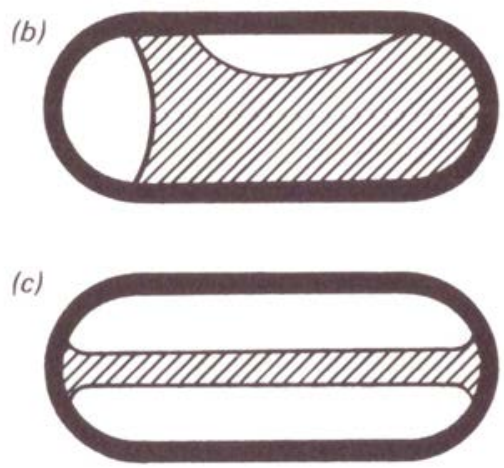

Figure 3. Schematic representation of three different stages of the removal of water from the interior of a rodshaped bacterium.

Since Venus is exceedingly hot at ground-level (about $450^{\circ} \mathrm{C}$ ) it is a matter of some surprise to find evidence of life existing there (Fig.1). The circumstance which makes life possible is the dual circulatory pattern of the Venusian atmosphere. From the temperatures and pressures measured by Pioneer Venus one can infer the presence of a lower convective zone from ground level to a height of about $30 \mathrm{~km}$. 
There is then still atmosphere up to about $45 \mathrm{~km}$, where the second convection zone begins. It is the non-moving in-between region from $30 \mathrm{~km}$ to $45 \mathrm{~km}$ which protects life in the higher zone from being quickly swirled down to the impossibly hot conditions near the ground.

Although bacteria are small and are able to ride easily with the atmospheric motions, there must nevertheless be occasional situations where a bacterium carried down to the base of the higher convective zone fails to find an up-current on which it can ascend again. Inexorable gravity will then cause the bacterium to fall slowly down through the in-between zone until it reaches the lower convective zone, where it will quickly be snatched downward and destroyed by the heat. It is therefore to be expected that the in-between zone will contain a thin haze of slowly falling doomed bacteria, and the existence of a thin haze between altitudes of $30 \mathrm{~km}$ and $45 \mathrm{~km}$ was indeed found by Pioneer Venus.

\section{Fall-Out of Bacteria, and Resupply of Nutrients}

From the data obtained by Pioneer Venus one can infer that the fall-out through the in-between zone would begin to denude a population of high-level bacteria in about 30,000 years, if the bacteria did not renew themselves. For renewal a supply of nutrients is required. Water, nitrogen, and carbon dioxide are amply available, but in addition to these main ingredients, other elements - sodium, magnesium, phosphorus, sulphur, chlorine, potassium, calcium, manganese, iron, cobalt, zinc and molybdenum - are needed in smaller proportions. It can be calculated that the fall-out through the in-between zone would carry about 10,000 tonnes of these essential ingredients each year from the higher convection zone to the lower zone. How, one can ask, may such a loss from the higher zone be compensated? The answer appears to be by the in-fall of meteoric material from space, rather than by gas diffusion upward from the lower atmosphere. The meteoritic supply to the Earth is known to be about 10,000 tonnes per year, and the supply to Venus - a very similar planet - should be about the same. The problem for gas diffusion upward lies in the lack of volatility of the compounds of many of the needed elements. There is no such problem for meteors in the size range from about $0.1 \mathrm{~mm}$ to $1 \mathrm{~cm}$, which are gasified as shooting stars on plunging at great speed into the high atmospheres of the Earth and of Venus.

The size distribution of particles measured for the upper clouds of Venus is essentially maintained in the middle and lower clouds, and in the haze zone of the in-between region. In the middle and lower clouds, however, there is also a considerably less numerous population of much larger particles. These we attribute to the tendency of bacteria to aggregate into colonies, a property that may well be helpful in preventing too much evaporation of water in the dry, hot conditions of the lower clouds.

The correspondence between the rate of supply of meteoric material and the rate of loss of essential nutrients down through the in-between region, about 10,000 tonnes per year in each case suggests that the quantity of bacteria in the clouds is nutrient-limited. The clouds have built up this population until the drop-out at the bottom equals the supply from outside. If the supply from outside were to cease then the population would decline steadily, until after a few tens of millennia it would be possible to see down to the ground-level of Venus. Such a situation may well have occurred in past times, only then there were no humans to observe the lower excessively heated surface zone of the planet.

Addendum: Further work on Venusian microbiota with an emphasis of transfers from Venus to Earth was carried out in 2008 by Wickramasinghe and Wickramasinghe (2008).

\section{References}

1. Coffeen, D.L. and Hansen, J.E., 1974. In Planets, Stars and Nebulae Studied with Photometry (ed R.Gehrels) University of Arizona Press

2. Knollenberg, R.G. and Hunten, D.M., 1979. Clouds of Venus: Particle Size Distribution Measurements, Science, 203, 792-795

3. Wickramasinghe, N.C., 1973. Light Scattering by Small Particles with Applications in Astronomy (Adam Hilger, London)

4. Wickramasinghe, N.C. and Wickramasinghe, J.T., 2008. On the possibility of microbiota transfer from Venus to Earth, Astrophys Space Sci, 317: 133-137 